\title{
12. The Future of Zeolite and MOF Materials
}

\author{
Eduardo Falabella Sousa-Aguiar, ${ }^{1}$ Pedro Augusto Arroyo, ${ }^{2}$ \\ Maria Angélica Simões Dornellas de Barros ${ }^{2}$ and \\ Jussara Lopes de Miranda ${ }^{3}$
}

${ }^{1}$ Federal University of Rio de Janeiro (UFRJ), School of Chemistry, Department of Organic Processes, Centro de Tecnologia, Bloco E, Av. Athos da Silveira Ramos, 149 - Cidade Universitária, 21941-909, Rio de Janeiro-RJ, Brazil.

${ }^{2}$ State University of Maringá (UEM), Department of Chemical Engineering, Centro de Tecnologia, Bloco D9o, Av. Colombo, 5790, - Jd. Universitário, 87020-900, Maringá - Paraná, Brazil.

${ }^{3}$ Federal University of Rio de Janeiro (UFRJ), Institute of Chemistry, Centro de Tecnologia, Bloco A, Av. Athos da Silveira Ramos, 149 - Cidade Universitária, 21941-909, Rio de Janeiro, Brazil.

Keywords: Adsorbent, technical catalyst, hydrogen storage, cracking, devices, commercial

\section{Introduction}

Zeolites were discovered in 1756 by the Swedish mineralogist Axel Friedrik Cronstedt [1], who recognized in the mineral stilbite (the first reported zeolite) a new class of hydrated aluminosilicates of the alkali and alkaline earths. He observed that upon rapidly heating stilbite produced large amounts of steam from water that had been adsorbed by the material. Hence, Cronstedt called the mineral a 'zeolite' (derived from two Greek words, meaning boiling stone). From that date on, several authors have described the properties of zeolite minerals, including their adsorption properties and reversible cation exchange and dehydration. In 1932 McBain coined the term 'molecular sieve', defining porous solid materials that act as sieves on a molecular scale [2]. Richard M. Barrer [3-5] began his pioneering work in zeolite adsorption and synthesis in the decade from 1930 
to 1940. He presented the first classification of zeolites based on molecular size considerations in 1945. In 1948, he reported the first definitive synthesis of zeolites.

The work of Robert Milton [6] and Donald Breck [7] of the Linde Division of Union Carbide Corporation deserves special attention. Between 1949 and 1954 they developed several zeolites, such as types A, X and Y, which had commercial applications in separation and purification. Mobil performed one of the first commercial applications of synthetic zeolites as catalysts, using $\mathrm{X}$ zeolite as the main component of cracking catalyst, in 1962. Moreover, in 1967, Mobil published the synthesis of new zeolites (beta and ZSM-5), which had a rather high silica-to-alumina ratio. The work carried out by Grace cannot be disregarded. In 1969, Grace introduced the first modification of $\mathrm{Y}$ zeolite, which underwent steaming to produce the well-known ultrastable Y zeolite, USY. It must be borne in mind that such zeolites are still being used in commercial cracking processes.

Later, in 1974, zeolite NaA produced by Henkel and Degussa was tested as a component of commercial detergents, opening a new window for zeolites' application. In fact, A zeolite currently accounts for more than twothirds of the total world consumption of synthetic zeolites.

Last but not least, due to the importance thereof in terms of consumption, natural zeolites have to be mentioned. Natural zeolites account for almost $60 \%$ of the total world consumption of zeolites. The main natural zeolites include minerals capable of ion exchange, such as clinoptilolite, chabazite, and Mordenite. China is the largest producer of natural zeolites, reaching almost $70 \%$ of global production in 2016; South Korea, Turkey, and Japan follow. The main use for natural zeolites is as a cement additive, to produce a slower-hardening and stronger product. Other major applications are as a nutrient-release agent in soil conditioners, in animal and poultry nutrition, and as an odour control agent in animal litter.

Synthetic zeolites are used mainly as detergent builders, catalysts, and absorbents/desiccants. As previously mentioned, the largest-volume use for synthetic zeolites is as a builder in home laundry detergent, accounting for almost $70 \%$ of the total. FCC catalysts are the second-largest synthetic zeolite use, with about $18 \%$ of the total volume. Consumption for adsorbent/desiccant applications represents the smallest share, but will be the fastest-growing market, driven by the recovery of construction markets use (as a desiccant in insulated multiglazed windows), the natural gas market (as a drying agent), and environmental applications (trapping volatile organic compounds, VOCs, to prevent release into the environment). 
The importance of zeolites has progressively increased since the pioneer publications of Barrer about synthesis and adsorption in the 1930s. Since then, catalytic applications, ion exchange as well as adsorption spread all over the scientific and industrial community. Around the 80's SAPO, MeAPO, TS1, MCM and UOP-Norsk Hydro structures were synthesized for catalytic purposes. Big industries such as Chevron and Union Carbide are relevant protagonists in this process. In the following decade mesoporous zeolitic frameworks found their role in the catalytic processes [8]. It is worth mentioning that the past fifty years have seen a tremendous progression in the generation of innovative molecular sieve materials. Indeed, since the discovery of traditional aluminosilicate zeolites, advances have been made towards the synthesis [9] of microporous silica polymorphs, microporous aluminophosphate-based polymorphs, metallosilicate and metallophosphate compositions, octahedral-tetrahedral frameworks, mesoporous molecular sieves, and, most recently, hybrid metal-organic frameworks (MOFs). Nevertheless, most of these very interesting new materials still call for industrial applications.

There are several reasons why zeolites have become the preferred catalyst for many reactions of industrial importance, as well as undefeatable adsorbents and ion-exchangers. The following characteristics must be depicted $[10,11]$ :

a) Thermal stability - surely, this is the paramount reason for the selection of zeolites as catalysts for high temperature reactions. Most of the zeolites remain unaffected by temperatures as high as $65^{\circ}{ }^{\circ} \mathrm{C}$. For zeolites presenting high silica-to-alumina ratios, structural collapse becomes significant only at temperatures as high as $1000{ }^{\circ} \mathrm{C}$.

b) Acidity - zeolites exhibit much higher acidity than the earlier amorphous silica-alumina catalysts. Zeolites also present both Brønsted and Lewis acid sites. The density of these acid sites is related to the silica-to-alumina ratio (SAR) in the zeolite framework. In general, the following parameters affect the overall acidity of a zeolite:

- nature or type of the acid sites

- density or concentration of the acid sites

- strength distribution of the acid sites

- location of the acid sites within the zeolite framework

- geometric distribution of the acid sites over the zeolite crystals.

c) Shape selectivity - pore dimensions within the zeolite frameworks are often similar to the sizes of the molecules participating in the reactions, 
which they catalyse, generating a strong influence on the selectivity of such reactions.

d) Concentration effects - concentration effects are related to the concepts of hydrophilicity or hydrophobicity of the zeolites, affecting the reaction selectivity. Such properties may be fine-tuned when zeolites are being synthesized, producing specific zeolites for a given purpose.

e) Ion-exchange characteristics - zeolites spontaneously undergo cation exchange. Such property makes zeolites undefeatable materials for water treatment.

f) High specific surface area - zeolites may present a rather high surface area, and are therefore excellent adsorbents and desiccants.

What is the future of zeolites and zeolite-like materials as far as industrial and commercial applications are concerned? This rather difficult question is the main target of this chapter, in which we discuss the potential uses of these spectacular materials, bearing in mind that zeolites are considered inert materials and not harmful to the environment. Hence, in a world in which environmental protection is a major concern, one may forecast a brilliant future for zeolite-type materials. Besides the use as catalysts, such solids have also increased their importance in the field of adsorption and ion exchange processes. It is difficult to separate them, as most processes involve, somehow, both phenomena. This chapter firstly describes this traditional use. Then, novel applications are presented. Last but not least, some comments about the future of these still potentially unexplored materials are made.

\section{Zeolites and zeolite-type materials as adsorbents and ion exchangers}

Zeolites are well-known adsorbents and ion exchangers. Nobody doubts it. It is possible to find zeolites in a wide range of applications. As well highlighted [12], zeolites find application in animal nutrition, wastewater treatment, soil fertilization and zeoponic cultivation, construction materials, cellulosic and sugar industrial uses, etc. As already mentioned, this is a consequence of their thermal stability, acidity, shape selectivity and high surface area. Today, more than 230 different zeolite frameworks have been synthesized and many more will be in the near future. Zeolites are molecular sieves and their frameworks are decisive in separation process, as such they are a major driving force for research in this area. 


\subsection{Traditional use of zeolites as adsorbents and/or ion exchangers}

Synthetic and natural zeolites are challenging. From filter media in swimming pool water treatment to complex hybrid process, each different use is simply incredible. The crystalline structure and high purity of synthetic zeolites enhances reproducibility wherever applied, although, unfortunately, costs are sometimes prohibitive. Nevertheless, zeolites find their way in direct connexion with green technologies.

One of the most traditional uses of zeolites is related to the removal of toxic metals from the environment because of the ion exchange properties followed by some multilayer adsorption. Breck [13] had already detailed such phenomenon. Up until the 9os, a large number of research projects were published. Highly charged cations are strongly attracted and exchanged in zeolitic sites. In spite of such knowledge, the commercial use of zeolites for toxic metal removal still faces some challenges. In fact, wastewaters are rich in a variety of contaminants - many of them are able to be attracted but some find diffusional restrictions. In such cases, the zeolitic channels may be inaccessible to the specific toxic metal or other particular cations of interest. This drawback may be overcome through treatments where other cations or partially charged organic molecules are retained or removed. This is the case in precipitation of filtration. Moreover, ion concentration higher than $5^{\circ} \mathrm{mg} \mathrm{L}^{-1}$ is not recommended as ion exchange or even adsorption taking into account diluted solutions.

It is noteworthy that, despite the small ionic radii of most heavy metals, lower than expected ion exchange is sometimes observed. Actually, heavy metals in an aqueous environment, even presented in synthetic solutions, are in their hydrated form; therefore, some diffusional resistances may be present. This is the case in $\mathrm{Mn}^{2+}, \mathrm{Zn}^{2+}, \mathrm{Cu}^{2+}$ and $\mathrm{Co}^{2+}$, whose hydrated ionic radius is similar to the free dimension channels of the clinoptilolite [14].

Mercury, for example, can be found in various forms. It is of great concern due to its high volatility and unquestionable toxicity related to neurodegenerative effects [15]. Elemental mercury $\left(\mathrm{Hg}^{\circ}\right)$, gaseous oxidized mercury $\left(\mathrm{Hg}^{2+}\right)$ and particulate-bound mercury $\left(\mathrm{Hg}_{\mathrm{p}}\right)$ are easily found in the flue gas. Unfortunately, around $90 \%$ of the total mercury is released in gaseous form. One possibility for mercury removal is by means of adsorption, mainly over activated carbons. However, such adsorbent has prohibitive factors in its commercial use - namely its high cost, some degradation when it is exposed to the high exhaustion gas temperatures, and its inefficiency for removal of mercury in its elemental form. Zeolites do not provide promising results either because of the weak physisorption, especially of $\mathrm{Hg}^{\circ}$, 
to the aluminosilicate framework. Nevertheless, its adsorption capacity is incredibly strengthened in silver impregnated zeolites. This happens due to the chemical affinity of silver to mercury, forming an amalgam. Besides removing mercury in elemental form, the saturated silver-zeolite adsorbent may be regenerated through heating to $400{ }^{\circ} \mathrm{C}[15]$, which aggregates tremendous advantages in continuous systems.

Other wastes that deserve attention are those rich in radionuclides. Such an effluent is commonly generated in nuclear power plants, nuclear weapons testing, medical examination or mining waters. ${ }^{134} \mathrm{Cs}$ and ${ }^{137} \mathrm{Cs}$, as well as ${ }^{226} \mathrm{Ra}$ and ${ }^{228} \mathrm{Ra}$, are some of the radionuclide elements commonly found in these wastewaters, which are easily treated through ion exchange in zeolites. It should be emphasized that these solids have an additional, important characteristic - resistance to radiation. It means that the final disposal of the radionuclide-containing zeolite will not harm the environment. This was the case when zeolites mitigated the impact of the accident at the Chernobyl nuclear power plant in Ukraine in 1986. The cationic form of radionuclides is successfully exchanged by the charge balancing sodium cation, generally present after the zeolite synthesis. Natural zeolites may be also used as cation exchangers. In order to improve removal efficiency, the zeolite surface may be modified. Some examples include the surface modification of Y zeolite with n-octadecyltrichlorosilane to remove ${ }^{137} \mathrm{Cs}$ and ${ }^{90} \mathrm{Sr}$ from aqueous to organic phases. In another tailored modification the balancing cation was replaced by different quaternary alkylammonium ions with promising results in the removal of ${ }^{121} \mathrm{I}$ and ${ }^{131} \mathrm{I}$ ions [16].

Natural zeolites can be applied in the remediation of soils rich in heavy metals. In addition to their high ion exchange capacity and low price, they exhibit significant selectivity even at low temperatures, releasing nontoxic metals such as $\mathrm{K}^{+}, \mathrm{Na}^{+}, \mathrm{Ca}^{2+}$ and $\mathrm{Mg}^{2+}$. Such features provide some extra advantages. This is the case when clinoptilolite is used in the sewage sludge to remove toxic metals with successful results [17]. It may supply alkalinity to the soil with the consequent precipitation of insoluble phases and the enhancement of metal sorption via surface complexation. Moreover, the ion exchanging process occurs regardless of the soil $\mathrm{pH}$. There is no need to emphasize the importance of more studies in this area, as leaching may be in some cases a drawback to sustainable recycling [18]. Ammonium can also be retained through ion exchange in natural zeolites. When removal of ammonium is considered, the released $\mathrm{Ca}^{2+}$ ions are used to precipitate phosphorous, which, along with ammonium, is also found in fertilizers [19]. It should be emphasized that phosphorous deserves special attention because its presence in soil or water is a result of 
the use of fertilizers, mostly added without adequate control, thus accelerating undesired eutrophication.

Removal of ammonium may also be important to improving wastewater treatment. In this case, ion exchange is not the main purpose of the process. Free ammonia released in anaerobic reactors inhibits methanogenic microorganisms. Thus, ammonia removal indirectly improves methane production [20]. Nevertheless, ammonia retained in the zeolite is also useful because its desorption provides enrichment in systems were nitrogen is needed. Then, the desorbed ammonia previously removed from wastewater acts exactly as the nitrogen source [21]. These new promising processes are astonishing! It means that adsorption and ion exchange properties have no limits and make zeolites the connexion for a sustainable world.

The ion exchange property of zeolites is not only limited to cation removal. In fact, tailored processes have been investigated to produce modified zeolites able to remove anions from the fluid phase. Some examples are related to the removal of the toxic anions arsenite, arsenate, chromate, cyanide and radioactive iodide. This is the case of zeolites treated with large cationic surfactants such as hexadecyltrimethylammonium amine (HDTMA). The resultant organo-zeolites have a wide range of applications because they can not only adsorb anions, but also adsorb or exchange cations in the remaining original sites [22]. It is also possible to tailor zeolites to multi-functional purposes (like adding magnetic properties to the support) or even redox purposes. These technologies are now in a pilot phase with the focus on environmentally friendly processing [23].

Curious uses involving hydrophilic properties, such as medicines to control diarrhea, are fundamental [24]. Moreover, it is already known that pharmaceuticals such as sulfa drugs and their metabolites are excreted in urine and feces. These low biodegradable compounds are not completely removed through conventional wastewater treatment and in most cases reach bodies of water. In this case, synthetic zeolites, such as HSZ-385, can adsorb molecules as long as the solution $\mathrm{pH}$ and $\mathrm{pK}_{\mathrm{a}}$ of each molecule favours the process, since the adsorption mechanism is based on the acid-base equilibria of the sulfa drugs and on hydrophobic interactions [25].

Zeolites can also be a support for drug release, such as non-steroidal anti-inflammatory compounds (NSAIDs). The surface of the modified zeolite releasing drugs through anion exchange as the sodic form of NSAIDs acts as the bound salt [26]. It means that the ion exchange capacity is not limited to cations, which opens a broad pathway for new discoveries. In fact, synthetic or even purified natural zeolites can be used as gastric 
antacid, anti-diarrheic, anti-hyperglycemic, hypocholesterolemic agents, also useful in the release of organic molecules, such as the anti-parasitic drug metronidazole or the antibiotic sulfamethoxazole, based on a strong dependence on the $\mathrm{pH}[27]$.

The application of zeolites as adsorbents is not restricted to liquid phases. In fact, separation of gases is one of the most important uses of zeolites. Indeed, our knowledge and the number of patents on this subject have increased dramatically over the years. This is a consequence of the flexibility of the design of adsorption systems. The successful use of zeolites in gas systems is due to the molecular sieve effect, whereby only small compounds are allowed to diffuse into the zeolite channels. Thermodynamic selectivity for each component in the gas mixture and even the kinetic selectivity, related to how rapidly the component diffuses into the channels, should be taken into account as well [28].

Zeolites act as adsorbents mainly in the removal of dilute impurities, which includes the classical use in gas drying, desulphurization or removal of organic compounds. Zeolites may be used to separate gases when increased purity and recovery are sought, or as a low-cost separation alternative. In these cases, a packed bed with one or several layers of zeolites is operated in PSA (pressure swing adsorption), TSA (temperature swing adsorption) or other mixed operation modes. The fundamentals of this wellknown technology have been extensively reported. In gas systems, pressure is of utmost importance and the contribution of zeolite-gas or gas-gas interactions should be carefully investigated. Synthetic zeolites are more appropriate to gas applications, although some studies related to natural zeolites have been reported [29].

As an application example, long stay patients at hospitals sometimes need medical oxygen for rehabilitation. Moreover, oxygen is absolutely necessary for astronauts, on space trips. Such pure gas may be generated through cryogenic distillation, water electrolysis or adsorption. The last one is, by far, the simplest technology. Of course, zeolites are used for such processes, such as LiLSX (Li-exchanged low silica X [30]). The light or noble gases may be separated with $3 \mathrm{~A}, 4 \mathrm{~A}, 5 \mathrm{~A}$ or ${ }_{13} \mathrm{X}$ zeolites [31]. Zeolites are of huge importance in natural gas storage or decontamination [32]. Finally, zeolites may be applied in gas chromatography as well.

These are some of the current application of zeolites directly linked to ion exchange and adsorption. New challenges keep being overcome with the help of such materials, from single ion removal to health care, and new possibilities continue to appear, in this research area thus remaining far from exhausted. 


\subsection{Novel applications of zeolites as adsorbents and ion exchangers}

The main objective of novel applications is not directly related to the sorption process, although it is the way in which they are achieved. This is the case when zeolites, coupled with carbons, are used as bactericides, in hybrid membranes, electrodes, capacitors, and sensors or even in energy storage processes.

Ion-exchange systems have been improved combining zeolite with different adsorbents such as activated carbons through extrusion and calcination. The silicate-carbon modified zeolite (SCMZ) is an example of this trend. Such a combined system yields advantages related to higher removal efficiency and easier cycle regeneration [33].

As an example, natural zeolite containing $\mathrm{Cu}^{2+}, \mathrm{Zn}^{2+}$ or $\mathrm{Ni}^{+2}$ may be used as a bactericide to pathogenic Gram-negative Bacteria Escherichia coli and Gram-positive Bacteria Staphylococcus aureus. This is a novel application in the tertiary stage of wastewater treatment [34]. Silver ion exchanged zeolites may also be applied as bactericide of Escherichia coli, Vibrio harveyi, Vibrio cholerae and Vibrio parahaemolyticus, commonly found shrimp pathogenic bacteria, providing an adequate and eco-friendly shrimp aquaculture [35]. In fact, silver is recognized by its bactericidal activity, influenced by the oxygen content $[36,37]$.

Bactericidal systems can also incorporate zeolites mixed with membranes, where the zeolite acts indirectly in the process, preventing fouling. One example is Linde type L (LTL) zeolite nanoparticles, which may be embedded in polysulphone ultrafiltration (UF) membranes. Such hybrid systems provide high anti-adhesion efficiency to both Escherichia coli and P. aeruginosa precisely because of the presence of the zeolite, although no bactericidal property was seen [38]. This is obviously a technological advance because bio-fouling is always a challenge to be overcome when dealing with membranes.

The zeolite-membrane system may provide more advantageous uses. Reverse osmosis is a widely used technology for desalination that however, has low resistance to oxidizing agents such as chlorine and low water permeability. These factors may promote operational problems that add to its high cost. Nevertheless, osmosis membranes containing zeolite nanoparticles seem to be a possible solution for such problems. Indeed, poly(arylene ether sulphone) reverse osmosis hybrid membrane containing EMT-type zeolite clearly enhanced chlorination resistance and improved desalination performance. It happens because zeolite nanoparticles modify membrane structure generating a high degree of cross-linking. As a 
consequence, a decrease in salt rejection and an increase in water permeation were observed [39]. Such advantages were also observed in thin filmnanocomposite membranes in which $\mathrm{NaY}$ zeolite was incorporated [40].

Natural zeolites particles may also be incorporated into polysulphone polymer membranes. Likewise, this combined system is efficient for ammonium removal with negligible leaching [41]. Membrane water treatments may separate even toxic ions. Unfortunately, the rejected ions are present in high concentrations and need further treatments to be recovered. This fact motivated investigations related to hybrid systems where membranes are combined with nanoparticles of zeolites. Then, the nanoparticleimpregnated membranes may efficiently remove and easily recover toxic metals. Advantages of this technology include high removal efficiency and the improvement in the hydraulic permeability of the membranes. Promising results for $\mathrm{Pb}^{2+}$ and $\mathrm{Ni}^{2+}$ removal in $\mathrm{NaX}$ nanoparticle impregnated polysulphone membrane have been reported [42].

The ion exchange membranes provided by zeolite-membrane hybrid systems have applications in electrodialysis for desalting brackish waters, simple production of table salt, or even reconcentrating brine from seawater. This is the case of PVC based-co-zeolite membranes. The zeolite enhances membrane electrical conductivity and ionic flux, which is undeniably a huge advantage [43].

Zeolites are such versatile solids that new discoveries have been published in many previously unexpected research areas. These aluminosilicates have been involved in electrochemistry, giving rise to a wide range of applications including electrocatalysis or its use in electrodes for analytical purposes. Zeolite-modified electrodes combine the intrinsic properties of a modifier with the specific electrochemical reaction. Such technology was introduced in the 8o's and its immediate popularity was a result of combining specific charge-transfer reactions with the zeolite ion exchange properties. Nowadays, zeolite-modified electrodes are seen as biosensors or even toxic metal electrodes in a simple device where size, shape or charge selectivity are considered [44]. In this context, Beta and L zeolites are successfully applied as glucose and acetylcholine biosensors [45] and zeolite $\mathrm{NH}_{4}$-Y modified carbon paste electrode (ZYMCPE) has been used in the voltammetric detection of toxic metals in ground waters or wastewaters [46].

Zeolites are also used in energy applications. When an electrical doublelayer occurs between a charge in a pore and the framework, an electrical, double-layer capacitive electrical energy storage is achieved using ultracapacitors. The zeolite-templated carbon has been studied with extremely positive results in the capacitor performance. Moreover, storing solar energy in zeolitic 
systems is a reality. It is based on simple principles based on their hydrophilic properties. When water is adsorbed, heat energy in the zeolite is released. On the other hand, when desorption occurs, heat energy is stored in it. This is of course an important application related to renewable energies. Zeolite hydrophilic properties are also applied in the measurement of humidity. Capacitors coated with zeolite films may detect humidity through the electrical properties of this material, which is a function of the $\mathrm{Si} / \mathrm{Al}$ ratio [47].

These are some of the novel applications of zeolites. Indeed, the ion exchange and adsorption properties of such materials generate infinite possibilities. It may be surprising that although these materials have been known for almost three centuries, it was only in the second half of the twentieth century that scientists started to investigate zeolite hybrid systems. From now on, many more applications are expected.

\subsection{The future of zeolites as adsorbents}

Zeolites are undoubtedly versatile solids. They are unique because of their ability to combine ion exchange and adsorption properties, as well as the possibility of modulating properties by different post-synthesis treatments or synthesis modifications, in the desired molecular sieve for a specific process. Consequently, the more zeolites are investigated, the more applications are reported even in their traditional uses. The examples discussed above represent only a small contribution of the benefits zeolites can bring to the environment. Unfortunately, moving forward from laboratory research to commercially obtained technologies is a big step.

Frequently, effluents contain a large number of contaminants, with different structures, charges and toxicity. In many cases, a comprehensive knowledge of the molecule is not easily accessible. This is the case of dyes or other organics produced by trade secret processes. Moreover, toxic metals are also found in real effluents. Indeed, zeolites have a potential use in all types of wastewater treatment. Nevertheless, the development of new ion exchange/adsorption units is still hampered by the complexity of real effluents. These contain a wide diversity of molecules competing both with each other and with inorganic toxic metal ions for the zeolite sites. In this context, hybrid zeolitic systems are an important field to be explored. Mixing zeolites with activated carbons or membranes produces more selective removal with higher efficiency with commercial and technological acceptance.

The future of zeolites is not restricted to wastewater treatment. For instance, in drug delivery, a large variety of pharmaceutically active 
compounds (PhACs) may be desorbed from zeolites in the adequate doses. This is another research field with large potentiality as zeolites are completely harmless when ingested.

The importance of zeolite in gas phase adsorption mainly in the removal of contaminants $\mathrm{CO}_{2}$ and $\mathrm{H}_{2} \mathrm{~S}$ present in the natural gas and biogas as well as $\mathrm{CO}_{2}$ capture is also noteworthy. In recent years, this research field has received great attention as an alternative technology, ss shown previously in this book.

Of course, the presence of zeolites in electrodes, capacitors or any other system where an electric field is involved is a new technological branch, and should not be overlooked. One point that should especially be taken into account is related to energy storage, which is of great concern to the modern world.

Therefore, zeolites may be present in such a wide range of possibilities that restriction of their use in only one research field is deemed completely unacceptable. In any investigation where ion exchange or adsorption is required, the use of zeolites should never be discarded at the outset.

\section{Zeolites as catalysts}

It is worth highlighting that zeolites will continue to hold a strong position offering innovative solutions in catalytic processes. However, characteristics of the product slate required by the market will determine the use of traditional or new zeolites. In general, the following features concerning hydrocarbons, are to be considered [48]:

- light olefins from $\mathrm{C}_{3}$ to $\mathrm{C}_{5}$ as raw materials for petrochemicals or for the production of clean, good quality fuels

- highly branched paraffins from $\mathrm{C}_{5}$ to $\mathrm{C}_{12}$ for the gasoline pool, or longer and slightly branched paraffins for the kerosene and gas oil pools

- specific molecules such as first and/or second generation intermediaries in petrochemicals: alkylmonoaromatics in particular. The development of processes of inter-transformation of these aromatics can certainly be expected.

\subsection{Cracking catalysts}

The first commercial use of catalysts for cracking occurred in 1915 when A. M. McAfee developed a batch process using aluminium chloride (which 
was a traditional Friedel Crafts catalyst known since 1877) to promote the cracking of heavy petroleum oils. Nevertheless, the prohibitive cost of the catalyst prevented the widespread use of McAfee's process at that time. Since then, several catalysts have been used for cracking, being historically subdivided into the following three main groups:

- Natural catalysts - clays, such as bentonite or montmorillonite, would undergo acid treatment to remove $\mathrm{Na}$ and $\mathrm{Mg}$, thereby increasing their acidity,

- amorphous catalysts - these were gels of silica and alumina, resulting from the reaction of $\mathrm{Na}_{2} \mathrm{SiO}_{3}$ and $\mathrm{Al}_{2}\left(\mathrm{SO}_{4}\right)_{3}$. There were two types of such catalysts, low alumina (10 to $15 \mathrm{wt} . \%$ of $\mathrm{Al}_{2} \mathrm{O}_{3}$ ) and high alumina (2O to 30 wt. $\%$ of $\mathrm{Al}_{2} \mathrm{O}_{3}$ ).,

- crystalline catalysts - micro-spheres $(40-150 \mu \mathrm{m})$, having a crystalline zeolite as the main component.

Indeed, Houdry was the first one to use acid-treated bentonites as cracking catalysts, back in 1936. In the 1940s, silica-alumina catalysts were synthesized, showing a great improvement in performance when compared with clay-based catalysts. Early synthetic amorphous silica-alumina catalysts contained about 13 wt.\% of $\mathrm{Al}_{2} \mathrm{O}_{3}$ (low alumina), however, in 1955, the content of $\mathrm{Al}_{2} \mathrm{O}_{3}$ had increased to about $25 \mathrm{wt} . \%$.

In 1962, the most important catalytic breakthrough in the FCC process took place, when a component, known as zeolite $\mathrm{Y}$, was added to the active alumina catalyst. By adding small amounts of zeolite into the matrix of the traditional silica-alumina catalyst, a new catalyst was produced. This catalyst had an outstanding performance, much better than any catalyst before. The zeolite catalyst greatly improved gasoline yield (Table 1). The first commercial zeolite catalysts were introduced in 1964, and zeolite catalysts continue to be used today. However, that gasoline produced via the pristine zeolite-containing catalysts presented a lower Research Octane Number (RON). This was later related to the fact that zeolites, having a very high density of acid sites, were increasing the Hydrogen Transfer Reaction (HTR), as described next [49]:

$$
3 \text { Olefin }+ \text { Naphthene } \rightarrow \text { Aromatic }+3 \text { Paraffin }
$$

Such reaction is detrimental to the gasoline quality since it reduces the RON of the products. For that reason, zeolites have undergone several types of modification, which aim at reducing hydrogen transfer, thereby increasing the gasoline RON. 
Table 1. Main properties of the first zeolite-containing catalysts.

\begin{tabular}{ll}
\hline Type & Main feature \\
\hline Coke formation & Zeolite-containing catalysts reduced coke formation \\
Gasoline yield & Zeolite-containing catalysts increased gasoline yield \\
RON & Zeolite-containing catalysts reduced RON due to \\
& higher HTR \\
\hline
\end{tabular}

Among current FCC catalysts, a very high number of formulations may be found. However, regardless of their formulation the catalyst components may be classified as follows [11]:

a) Active component - responsible for most of the catalyst activity, are usually faujasites (Y zeolites). Currently, another zeolite has also been used (ZSM-5).

b) Matrices - promote bottoms conversion, increasing the overall activity of the catalyst. They must present a certain tolerance to $\mathrm{Ni}$ and $\mathrm{V}$, to nitrogen-containing compounds and, whenever possible, promote DESOX effects. They must also present binding properties.

- Active matrix - normally, the active matrix is an alumina, which is acidic, although less acidic than the zeolite. On the other hand, aluminas display much larger pores than zeolites, therefore they promote pre-cracking of heavier molecules,

- Inert matrix - normally, the inert matrix is a clay, such as kaolin, used to confer physical properties.,

- Synthetic matrix - the synthetic matrix is actually a binder that keeps all other components bound together in the final catalyst.

c) Functional ingredients - ingredients added to the catalyst to perform a specific function (i.e. traps to capture vanadium compounds).

\subsubsection{The zeolite component}

As previously mentioned, the zeolite component is the most important component in the FCC catalyst, being able to provide the catalyst with both convenient activity and selectivity. In FCC catalysts, the zeolite employed is faujasite (FAU). The $\mathrm{Si} / \mathrm{Al}$ ratio of the prepared Y zeolite is an important feature of the parent zeolite, since the higher $\mathrm{Si} / \mathrm{Al}$ ratio, the more stable it is against acid and hydrothermal dealumination. 
The zeolite is synthesized in its Na-form, which is non-active, since acidic sites (Brønsted acid sites), responsible for the formation of carbocations and hence cracking reactions, are not present. Thus, the NaY zeolite must undergo ion exchange with either ammonium or rare earth ions to prepare the ammonium/RE form of the zeolite, which will generate the acidic form HY upon calcination.

\section{RE-Yzeolites}

The introduction of rare earth elements (RE) in the zeolitic component, via ion exchange, followed by a calcination step, is one of the most important modifications carried out in the process of FCC catalyst preparation, since it increases both the stability of the zeolite and the overall activity of the catalyst. Furthermore, calcination promotes framework dealumination, changing acidic and textural characteristics in the zeolite.

Since RE do increase Brønsted acidity [50], RE affect both activity and selectivity. The higher the ionic radius of the $\mathrm{RE}$ atom, the higher the acidity generated in the zeolite. Since HT increases with the increasing zeolite acidity, the higher the atomic radius of the RE atom, the higher the HT. Generally, RE favour HT, lowering RON by reducing olefin concentration in the gasoline. Nevertheless, since RE also affect the zeolite stability [51], sometimes evaluation may be rather misleading. It must also be borne in mind that industrial results show that RE seem to have little influence on the gasoline MON. Finally, rare earths also play an important role in preventing deactivation by metals [52] as they are a very effective vanadium trap.

Rare earths are facing a terrible problem of increasing price and decreasing availability. Thus, the removal of these ingredients from the FCC catalyst composition has been a constant effort. However, the total removal of rare earth elements from the zeolite component of an FCC catalyst would result in a considerably detrimental effect in most FCC operations due to the lower activity and worsened product yield slate, not to mention a problem of higher vanadium deactivation. For that reason, other elements such as $\mathrm{Ca}$ and $\mathrm{Cr}$ have been tried, though without encouraging results.

\section{$\mathrm{NH}_{4}-$ Y zeolites}

$\mathrm{NH}_{4} \mathrm{Y}$ zeolites must also undergo thermal treatments, in order to generate Brønsted sites upon calcination. Calcined ammonium-exchanged Y-zeolites are often known as USY (ultrastable Y zeolites). Calcination is, however, a very complex step, since several reactions may take place. Furthermore, zeolites undergo structural modifications upon calcination. Calcination generates acidic sites, but also promotes dealumination, 
generating aluminium species known as EFAL (extra framework aluminium). The removal of framework aluminium changes the unit cell size of the zeolite. Calcination also generates mesoporosity, probably because part of the framework is destroyed as dealumination proceeds.

Several factors affect the characteristics of the zeolite after calcination. Among them, the following deserve attention:

- Si/Al ratio of the parent zeolite,

- Na content of the exchanged zeolite,

- steam partial pressure during calcination,

- temperature of calcination,

- calciner geometry (deep bed versus shallow bed).

\section{Hierarchical zeolites and the concept of accessibility}

The characteristics of current feedstocks, in which one may observe a growing content of heavier molecules, has drawn the attention of the zeolite community to the concept of accessibility. Recent literature has shown the importance of accessibility in cracking catalysts [53-6o]. Accessibility is a parameter related to the mass-transfer characteristics of an FCC catalyst, which may be a selectivity-determining step. Indeed, the geometric disposition of components in the final catalyst does affect selectivity in the cracking process. In fact, reducing diffusional effects improves gasoline selectivity.

As far as increased accessibility of the zeolite component is concerned, the development of methods to increase mesosurface area, via the following methods was the strategy adopted to cope with cracking of heavier molecules:

a) the synthesis of zeolites with larger micropores,

b) reduction of the crystal size,

c) introduction of additional pores of larger sizes (mesopores).

Such methods may be divided into two categories: bottom-up or primary syntheses, and top-down or post-synthetic modification. In both cases, hierarchical zeolites are generated. Notably [21], the term 'hierarchical zeolite' encompasses any zeolite with at least a secondary pore-structure system and, therefore, 'mesoporous zeolite' should be considered as a subclass of the former because it defines the size of the additional porosity as falling within mesopore range, that is, between 2 and $50 \mathrm{~nm}$.

Amid the characteristics that might have an effect on the accessibility of zeolites, the crystallite size, which affects the external surface area 
directly, deserves special attention. Thus, papers concerning the importance of small-crystallite zeolites on the cracking of bulky molecules are being revisited [58-6o].

A new commercial technology [61] (Rive's technology) to increase the accessibility of the zeolite component has been launched. It improves the characteristics of zeolite $\mathrm{Y}$ by creating a network of intermediate sized ( 2 to $6 \mathrm{~nm}$ ) mesopores throughout the crystals of zeolite Y. Performance benefits resulting from Rive's zeolite were reduced coke formation, improved bottoms upgrading, and increased olefinicity of the cracked products.

\section{Zeolites as functional ingredients}

The demand for light olefins such as ethylene and propylene has increased a lot in the last decade. Steam cracking of hydrocarbons has been the major source of light olefins for more than half a century. Nevertheless, recent studies have reported that ethylene and propylene can also be commercially produced through the cracking of hydrocarbons over modified ZSM-5 zeolites [62]. In this case, ZSM-5 would behave as a functional ingredient in the FCC process, or rather, an ingredient added with a specific function. As a functional ingredient, $\mathrm{ZSM}-5$ could be embedded in the final catalyst or used as a separate particle to be blended with the traditional catalyst.

ZSM- 5 has been used as an FCC additive for boosting gasoline octane number. Interestingly, the use of ZSM- 5 also increases $\mathrm{C}_{3}$ and $\mathrm{C}_{4}$ LPG selectivity with a concurrent decrease in gasoline yield. The yielded LPG consists predominantly of olefins, whereas there is essentially no change in dry gas (C2-) or coke selectivity.

However, a significant change in gasoline composition takes place.

Both the decrease in gasoline molecular weight and the increase in $\mathrm{C}_{5}$ hydrocarbons are important for an increase in the gasoline octane number. Since the total volume of gasoline is reduced due to the decrease in $\mathrm{C}_{7+}$ aliphatics, the concentration of aromatics and naphthenes in the gasoline is higher, which helps boost the gasoline octane number.

Regarding chemical modifications, treatment of ZSM-5 with phosphorus compounds $[63,64]$ seems to be an interesting route to improving selectivity to light olefins in cracking reactions. After phosphorus treatment, the strong acid sites of the original zeolite are replaced by an increased number of weaker acid sites, with a concentration, which increases upon steam treatment. Interestingly, the combined treatment of phosphorus/ rare earths [65] results in an improvement in both stability and activity. Apparently, rare earths reduce aromatics formation on the external surface 
area of the zeolite, whereas phosphorus reduces the loss in activity caused by dealumination.

\subsubsection{The future of zeolites in cracking}

Vogt and Weckhuysen [66] have recently published an interesting review paper concerning FCC catalysts. It is clear that the role of zeolites as the most important component in FCC catalysts is certainly undisputable. Although new materials have been synthesized with several properties similar to those displayed by zeolites, such as acidity and selectivity, none is capable of replacing Y zeolites in the cracking process. Nevertheless, the characteristics of the refining industry demand modifications in the zeolite component in order to cope with several requirements concerning, for instance, heavier feedstocks or more environmentally friendly products. Among the improvements and modifications that could be carried out, the following deserve special attention:

a) Increased silica-to-alumina ratio (SAR) of the NaY zeolite - innovative routes of synthesis of $\mathrm{Y}$ zeolite with a higher silica-to-alumina ratio (higher than 6) must be proposed. The current routes of synthesis of high SAR NaY zeolites are very time-consuming, causing a decrease in capacity in the industrial plant.

b) Increased accessibility - synthesis of small crystallite zeolites, with high external surface area, is an alternative bottom-up method to increase accessibility. Such zeolites are, however, more unstable, therefore requiring a higher SAR. Moreover, the synthesis of hierarchical Y zeolites is also an excellent option for higher accessibility.

c) RE substitution - RE are becoming scarce and expensive. New options to replace RE elements in the formulation of the zeolite must be discovered. It should be born in mind, however, that the role of RE is rather complex, since they increase both activity and stability.

d) Zeolites in the FCC particle - It is important to bear in mind that the zeolite is a component of a rather complex system, that is to say, the FCC catalyst. Hence, interactions between the zeolite and other components should not be disregarded. Zeolite/binder interactions are often responsible for a deep loss in activity, since the binder causes micropore blocking. For that reason, new systems, or rather, the concept of compounding has to be taken into account. Zeolites are not to be considered as a single particle, but a component of a complex system in which several interactions do take place. The future calls for new technologies of FCC particle generation in which the properties of Y zeolite may be fully employed. 


\subsection{Hydrocracking/hydroisomerization catalysts}

In the next decade, clean fuels requirements will have a major impact on the way in which refineries are configured $[67,68]$. The Fluid Catalytic Cracking Unit (FCCU), in particular, will require more extensive integration with hydroprocessing units to produce low sulphur fuels, while meeting refinery emissions regulations. In fact, not only are cleaner products requested, there is also a significant switch from gasoline towards gasoil/diesel worldwide, with decreased fuel oil demand. Hence, hydrocracking and hydroisomerization processes are gaining much interest. Furthermore, the rebirth of gas-to-liquids/coal-to-liquids processes, which require an upgrade step, will also put the focus on hydroprocessing technologies.

Indeed, new mild hydrocracking (MHC) technologies will enable the optimization of FCCU and hydroprocessing refinery assets to produce high-quality-clean-fuels at lower costs. Innovative process allows the refiner to produce clean diesel and improve the quality of the FCCU feedstock. New UOP technology, for instance, features a unique flexibility to produce ULSD, improve cetane number and diesel cold-flow properties by the simple expedient of a catalyst change-out in the same reactor.

\subsubsection{Hydrocracking}

It has been known for a long time that hydrocracking involves a bifunctional mechanism where a 'metal' function is responsible for hydrogenation/dehydrogenation reactions (although in many hydrocracking catalysts the metal function is actually given by a transition metal sulphide phase), whereas an acidic function is responsible for isomerization and cracking reactions. A proper balance between 'metal' and acidic functions must exist in the ideal hydrocracking catalyst. The hydrogenation/dehydrogenation function must be strong enough to adequately supply the acidic sites with olefin molecules for carbenium ion production and quickly hydrogenate the product olefin to avoid secondary cracking [69].

Bouchy et al. [69] have observed that the potential secondary cracking augments with an increased average residence time of olefinic intermediates in the vicinity of acid sites. Therefore, any diffusional limitation or confinement effect resulting in a too strong adsorption of the intermediates should be minimized. For this reason, amorphous mesoporous supports, like silica-aluminas $\left[7^{\circ}-72\right]$ have been more frequently used than zeolite supports and, when these are used, a zeolite with little shape selectivity, such as USY, is the usual choice. 
Ultrastable Y zeolite (USY) and Beta zeolites are relatively wide-pore zeolites, not displaying shape selectivity in hydrocracking. This leads to a very wide product distribution [73]. Therefore, the search for alternative zeolites is a must.

The use of zeolites with straight parallel narrow pores, such as ZSM-22, leads to the phenomenon known as pore mouth catalysis [74-80], which brings about a high selectivity for isomerization near the extremity of the hydrocarbon chain but also undesirable light hydrocarbons production.

In a very interesting contribution, Thybaut et al.[73] speculated whether there could be some zeolite pore structure in which the adsorption of both extremities of the linear hydrocarbon chain would occur inside narrow straight pores, whereas the middle part would be located within wide cavities, where branching reactions might take place, eventually leading to cracking at the desired middle part of the chain to maximize the production of valuable hydrocarbons. A hierarchical zeolite combining Y-zeolite supercages with ZSM-22 segments would present such outstanding properties. As a matter of fact, a simulation of the reaction of n-dodecane in this type of structure using a single-event microkinetic model has been carried out. The results indicated that with this type of structure the percentage of C6 products obtained by central cracking in the chain can be increased from $25 \%$ with non-shape-selective Y zeolite, to up to $93 \%$. It has been then proposed that this is a promising approach in the development of zeolite catalysts for the selective hydrocracking of waxes into middle distillates. Synthesis of such materials is certainly the future in this area.

\subsubsection{Hydroisomerization/dewaxing}

These processes aim to produce good base oils for lubricants. The most important properties of lubricating oils are sulphur content, pour-point, cloud-point, oxidation stability and viscosity index. Viscosity index (VI) is a standard empirical measure, widely accepted by the lubrication industry, inversely related to the change in oil viscosity with temperature. Normal grade base oils (groups I and II, according to API classification) have VI's in the 80 to 119 range. High-grade group III oils are produced by modern hydroprocessing technology in petroleum refineries, including hydroisomerization, and have VIs above 120. Proper design of catalysts and process conditions for hydroisomerization/dewaxing has to take into account the molecular characteristics desired for obtaining proper cold-flow properties without compromising VI. It is often accepted that increasing the degree of alkane branching decreases the VI of the oil [81]. Miller et al. [82] suggested that minimizing overall branching while maximizing the branching 
towards the middle of the lubricant base oil molecules provides fluids with a high VI and low pour points.

It is therefore reasonable to admit that HIDW catalysts should be designed in order to promote branching of the largest possible fraction of the $n$-paraffin molecules present in the feed, but limiting as much as possible the number of the branches. The occurrence of hydrocracking reactions should also be avoided.

Hence, catalysts that have a high hydrogenation activity and a low acidity are indicated for maximizing hydroisomerization versus hydrocracking [83]. Platinum or palladium, are generally found to be the most appropriate metallic phase for hydroisomerization/dewaxing catalysts, rather than mixed-sulphides or a base metal such as nickel.

Regarding the zeolite component, it must be selective for adsorption of linear alkanes and the pores should be small enough to limit the occurrence of branching reactions inside such pores. The formation of multibranched hydrocarbons would be deleterious for the VI. Such molecules are precursors of hydrocracking reactions. Medium pore zeolites and, especially, those with parallel straight pores and ten-membered ring pore openings. ZSM-22, ZSM-23, ZSM-48 as well as SAPO-11 have been shown to be excellent acidic components for HIDW catalysts for long-chain n-paraffins, as reviewed by Bouchy et al.[69]. In fact, the geometry of the pores thereof induces the pore mouth mechanism for short-chain paraffins. However, a second effect named key-lock mechanism [69], appears in long chain hydrocarbons. In this last type of mechanism, both extremities of the hydrocarbon chain penetrate neighbouring pores emerging at the zeolite crystal surface and the branching occurs in the central part of the chain by reaction on acidic sites at the external surface of the zeolite between pore openings.

Indeed, studies regarding the hydroisomerization of n-octadecane in a series of closely related zeolites of the ZSM- 48 family have been performed [69]. Maximal isomer yields of up to $77 \%$ at conversions approaching $100 \%$ were obtained in some cases and significant selectivity differences were observed between the different but related zeolites. This fact clearly indicates that even subtle differences in the arrangement of pore openings at the crystal surfaces, detailed topology of the zeolite channels, and concentration and position of aluminium atoms strongly influence the catalyst activity and selectivity.

It is therefore clear that the future of zeolites for hydroisomerization/ dewaxing lies in the search for innovative materials capable of providing outstanding performances based on both pore mouth and key-lock mechanisms. 


\section{Metal-Organic Frameworks}

MOF is the abbreviation for metal-organic framework, a designation coined by Yaghi [84] in 1995 to name a class of hybrid porous robust materials in which coordinated metal or metal clusters are connected/coordinated by bridged organic linkers, forming a crystalline welldefined range of frameworks. They have attracted great attention due their huge pore dimensions and tremendous superficial area associated with a chemical versatility, causing a fast development of the synthesis of new compounds. Several research groups have given different names to them, as can be seen in Table 2. The French group, Férey named new MOFs following the convention of the zeolite community, using three letters (generally associated with the geographic origin of the material) accompanied by a number, as in the series of MIL-n, for Materials of Institute of Lavoisier [85]. MOFs are also referred to as coordination polymers, although for some authors this terminology may cause confusion since it has its origin in the first hybrid open frameworks formed by isolated polyhedra or small metal clusters, which are unlike the extended dimensionality of the inorganic parts, able to give rise to channels, layers or 3 D frameworks [86].

Since then, there have been many books, reviews and articles on these compounds and their applications, which spread over storage energy, gas storage, $\mathrm{CO}_{2}$ capture, catalysis, supercapacitors, magnetic devices, luminescent compounds, drug delivery, water photolysis, water detoxification

Table 2. Some designations for hybrid metal-organic frameworks.

\begin{tabular}{ll}
\hline Abbreviation & Name \\
\hline MOF & Metal-organic Frameworks \\
IRMOF & Isoreticular Metal-organic Frameworks \\
ZIF & Zeolite Imidazol Frameworks \\
MIL-n & Materials of Institute of Lavoisier \\
UiO & University of Oslo \\
JUC-n & Jilin of University China \\
HKUST-n & Hong Kong University of Science and Technology \\
NOTT-n & University of Nottingham \\
ITQMOF-n & Institute of Chemical Technology (Spain) - Metal-organic Framework \\
BIFs & Boron Imidazolate Frameworks \\
ZMOF & Zeolite-like MOF \\
MOPs & Metal-Organic Polyhedra \\
POMOFs & Polyoxometalate-based metal-organic frameworks \\
\hline
\end{tabular}


and even compounds for disabling chemical weapons [87]. Some of these important applications of MOFs have already been discussed in previous chapters of this book. This contribution points out some of the challenges and outlooks of MOFs. To the readers, two main questions are suggested: 1) Have the researchers of MOFs fully dominated the tailoring of the construction of porous framework materials aiming for the functionality or final application of them? Or in informal language, have they finally dominated the Chemical tailoring land as it were the Legoland of our childhood? And 2) What is the future of MOFs?

\subsection{From modular chemistry to magic number ratios}

The initial conceptual design of MOFs [87] has proposed three challenges to be faced: 1 ) the control of the orientation and stereochemistry of building blocks in solid state to guarantee the targeted molecular architecture, 2) the synthesis of crystalline materials that can be fully characterized by single-crystal X-ray diffraction, and 3) reversible access to the pores with maintenance of the framework avoiding interpenetration even after the removal or replacement of the guest molecules.

Some strategies have been chosen in order to design and assemble MOFs based on what was initially called Modular Chemistry [87] and afterwards Reticular Synthesis [88]. These are:synthetic routes for achieving porous and crystalline modular networks using solvothermal, diffusion and gel techniques, the development of methods to obtain rigid non-interpenetrated structures containing pores with reversible access for guest molecules without affecting their structural integrity, and the discovery of new applications and properties of porous solid frameworks derived from tailoring their construction with the building blocks [87]. The schematic construction of these porous frameworks involves the inorganic part - the metal ion centers or nodes, and the organic part - the organic linkers that act as coordinator agents directing the assembly of a framework. An analogous terminology of zeolites has been adopted [89,9o] using the term Secondary Building Units (SBUs) for the units or entities which were not employed in the synthesis but formed in situ and are composed of molecular complexes and clusters connected by organic linkers [89-92]. The building blocks, on the contrary, were employed as synthetic units.

In order to obtain extended high porous frameworks, a careful selection of the organic linker and metal coordination environment should be done as well as a foresight of the topology derived from their connectivity. The 
<smiles>O=C(O)c1ccc(C(=O)O)c(Cl)c1</smiles>

a)

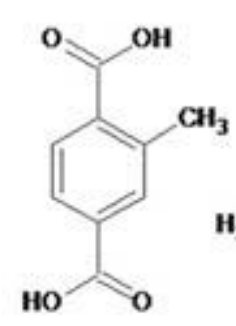

e)

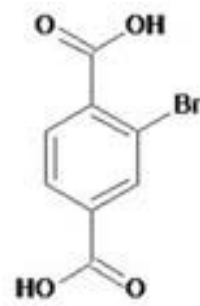

b)

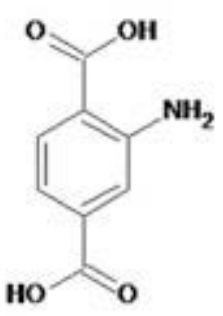

c)<smiles>O=C(O)c1ccc(C(=O)O)c([N+](=O)[O-])c1</smiles>

d)

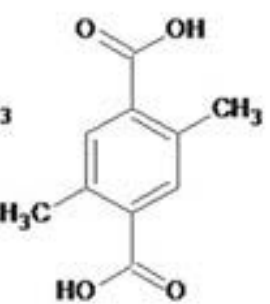

f)<smiles>O=C(O)c1ccc(C(=O)O)c(I)c1</smiles>

g)

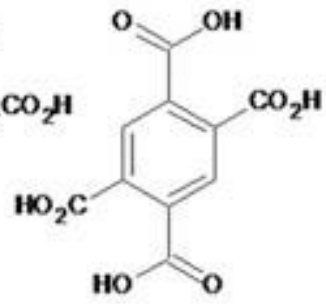

h)

Figure 1. Some of the dicarboxylic ligands employed in MOFs: a) 2-chloro-benzene-1,4-dicarboxylic acid, b) 2-bromo-benzene-1,4-dicarboxylic acid c) 2-amino-benzene-1,4-dicarboxylic acid, d) 2-nitro- benzene-1,4-dicarboxylic acid, e) 2-methyl- benzene-1,4-dicarboxylic acid,

f) 2,5-dimethyl- benzene-1,4-dicarboxylic acid, g) benzene-1,2,4-tricarboxylic acid, h) benzene1,2,4,5-tetracarboxyic acid.

organic linker should present a rigid disk-like conformation able to coordinate to the metal ion in a multidentate mode, easily acting as bridges that form the voids in the structure and enhance their thermal stability and robustness. Examples of organic linkers range from dicarboxylate ligands (Figure 1) to bypiridines, imidazoles and porphyrins [93]. The molar metal/ organic linker ratio should be high to help the multidentate coordination necessary for the framework construction.

The guest molecules, on the other hand, play an important role in preventing the interpenetration of the structures and also contribute to tailor the shape and size of the pores. These molecules should help in deprotonating the organic linkers and should not coordinate to the metal ions, being easily evacuated to render the formation of the pores and the metal vacancy coordination site [87]. Examples of these guest molecules are triethylamine ( $\mathrm{pKa}=11.01$ ), dimethyl formamide, alcohols and even water. It is interesting to notice that it was observed an isostructure and an identical X-ray powder 
diffraction for the very first synthesized MOFs of the $\mathrm{M}_{2}(\mathrm{BTC}) \cdot 12 \mathrm{H}_{2} \mathrm{O}$ series, where BTC is 1,3,5-benzenetricarboxylate and $\mathrm{M}$ can be Co, Ni and $\mathrm{Zn}$. The inclusion process of aromatic guest molecules was governed by electronic interactions rather than only shape or size [87].

Following the tailoring design, an immense variety of new MOFs combining the building blocks have been synthesized with the already reported number reaching up or more than 20,000 [94]. Curiously, in 1998, Yaghi et al. anticipated their application in removal of undesired substances from industrial water and in low-temperature catalysis and sensor developments. Nowadays, regarding the great variety of MOFs, not only Yaghi's predictions were fulfilled but also far extended.

By choosing the metal nodes (metal ion centers or clusters) and the organic linker, a tremendous variety of MOFs can be designed, making them a special class of porous and crystalline materials of a high degree of structural and functional tenability [95], properties that overcome other materials such as zeolites and activate carbons [85]. The great tunability of MOFs can explain the wide range of their applications that embrace very different areas including the initial and most known uses in capture, separation and storage of gases $[96,97]$, as well as catalysis [98], chemical sensors, optical luminescence, ionic conductivity, and non-linear optical behaviour [99].

\subsubsection{Post-synthetic modification}

The wish to choose different molecular building units may unfortunately, be restricted in synthesis, in some cases, due to limited organic linker solubility, chemical stability, thermal stability, functional group compatibility or even undesired polymorphs of crystalline MOFs [100].

In those cases, however, a post-synthetic modification (can be made by heterogeneous chemical reactions that functionalize MOF structures previously assembled [99] through two different approaches: either by modifying a) the organic linker or b) the central metal nodes.

a) Modification of organic linker - can be made by making specific changes in the covalent interactions involving the linkers or in their functionality or charge compensation, with electron or ion addition [100].

b) Modification of the central metal node - can be made through inclusion of a non-framework ligand to the metal ion [100] incorporation of alkyl or silyl groups to oxygen coordinated atoms or addition [101] of metals at node oxygen atoms [102].

Notwithstanding the post-synthetic modification, we can go beyond that. Farah et al. [103] proposed a replacement in the building block without 
disruption of the metal-linker bonds, which involves solvent-assisted linker exchange, non-bridging ligand replacement, and transmetalation. This approach allows the design of new MOFs, using parent MOFs as templates via single crystal transformations.

\section{The supermolecular building approach for new MOFs}

Several researches have worked on a different approach for designing new MOFs: the modification and expansion of their topology components. One target of that approach is to produce zeolite-like metal-organic frameworks (ZMOF) based on, and expanding, zeolitic networks. A recent review [104] reported the strategies for design and synthesis of ZMOFs, which can be done through:

a) expansion of the edge (edge-expansion) of traditional zeolites,

b) assembling from hierarchically superior building units, such as metalorganic cubes,

c) enlarging the tetrahedral building units,

d) building via organic tetrahedral nodes.

To continue the focus on topology, there are two recent approaches for design and construction of new MOFs: supermolecular building block (SBB) and supermolecular building layer (SBL).

The already familiar approach of molecular building blocks (MBB) for MOFs allows the introduction of desired properties and functionalities prior to the assembly process and synthesis by the previous selection of specific building blocks, but for what is called simple topologies, i.e. with a number of connectivity that ranges up to 8 or 10-12. Producing MOFs employing the MBB approach with connectivities higher than 12 becomes harder due to the difficulty in achieving the proper reaction conditions [104]. For this reason, Eddaoudi's group employed the SBB and SBL approaches, enlarging the number of the connectivities among polyhedral and layer structures, respectively, constructing more elaborate building units and elucidating the relationship between them and minimal edge-transitive 3-periodic nets [105]. This opens a new pathway for the design and construction of desired and yet hypothetical 3-periodic metal-organic polyhedral or layer MOFs.

\subsubsection{Magic number ratios: order at heterogeneity?}

The functionalization of MOFs has not been restricted to adding functional groups to the organic linkers. Multiple organic functionalities can be added to MOFs on a nanoscale producing new assembles with different applications. The insertion of nanoparticles into materials is not new, it can 
and is being done with MOFs. The question posed by Yaghi himself was how to control the resulting combination of heterogeneity and order when producing assemblies or composites by adding different multiple organic components to MOFs? [105]

The challenge is to obtain a framework with a heterogeneity component controlled even with a change of the environment in its structure. Although two different organic struts of rigid bones (one of a crown ether- $\mathrm{L}_{\mathrm{r}}$ structure and the other of a catenane- $\mathrm{L}_{\mathrm{b}}$ ) were added in a nanoscale to zinc nitrate in very different $\mathrm{L}_{\mathrm{r}} / \mathrm{L}_{\mathrm{b}}$ ratios. Both produced $\mathrm{MOF}-2 \mathrm{OoO}\left(\mathrm{Zn}_{4} \mathrm{O}\left(\mathrm{CO}_{2}\right)_{6}\right)$ with a 2:1 ratio. This magic number ratio of 2:1 between the two organic components, $\mathrm{L}_{\mathrm{r}}$ and $\mathrm{L}_{\mathrm{b}}$, was amazingly observed in MOF-20oo crystals, sometimes in different ratios (8:1, 6:1, 4:1, 2:1, 1:1, 1:2, 1:4, 1:6 to 1:8), even if the composition of the parent solution was varied by an order of magnitude in the synthesis. To explain this magic number, standard Monte Carlo simulations were done and revealed that this specific ratio is not derived from thermodynamically restriction but instead suggested that the two components were kinetically trapped during crystal growth [105]. Moreover, the calculations showed how to obtain different but controlled arrangements of component types by varying their non-covalent interactions or the topology in which they are added [105].

The idea of this Magic Number and the control of order in the heterogeneity opens an interesting new window: a new prediction that we may, in the future, combine the heterogeneity of biological materials with the robust properties of the synthetic compounds by arranging and controlling multicomponent types in solid frameworks.

\subsection{Expanding the MOFs Family: MOF composites and MOF derivatives}

Besides MOFs, even considering the huge variety of them, functionalized or not, composites and derivatives of MOFs have also been researched and synthesized enlarging their applications to a great extent.

MOF composites can be produced by integrating functional materials in order to obtain multifunctional compounds and very new technologicallyadvanced materials. In this perspective, MOFs may act as support substrates to assemble different kinds of compounds like graphene, carbon nanotubes (CNTs), nanorods, nanoparticles, metals, metal oxides, metal sulphides, complexes, and even enzymes, forming composites with very interesting performances in catalysis. These include $\mathrm{CO}_{2}$ conversion, 
photo-induced $\mathrm{H}_{2}$ generation, proton conduction, and magnetic behaviour. It is interesting to note that these multifunctional MOF composites not only present a behaviour that involves synergistically in all the components but may also have new properties [106].

On the other hand, MOFs can also be templates as sacrificial precursors to direct the formation of higher porous and organized nanoporous carbon materials via pyrolysis in a process called MOF-to-carbon (MTC). Graphene nanoribbons with excellent supercapacitor performance [106] have already been obtained employing MTC process.

\subsection{MOF devices \& applications: the MOF-based technology}

One of the hottest areas involving MOFs is the investigation in micro- and nanofabrication methods for MOF-based devices for a wide range of applications.

Due to their high degree of organization and porosity, associated with their self-assembly in ordered lattices, MOFs are being employed in device fabrication through different approaches for a great diversity of area. These include sensing, microelectronics, optics, micro-motors, molecular rotors, pollutant sequestration, energy storage and production, bioreactors, diagnostics and controlled drug release [107], some of which have been dealt with in detail in previous chapters of this book. As it is the case for zeolites, there are two different patterns to fabricate MOF-based devices as seen in Figure 2: the bottom-up, in which MOF crystals are grown in pre-defined locations, and the top-down, in which the transfer or removal of pre-existing MOF crystals is done in the material [107].

The prerequisite and challenge for the development of MOF-based technology is the spatial control over the location of MOF materials, regarded as a determinant step for design and fabrication of their devices. To face this challenge, a great variety of techniques are being pursued and employed for the fabrication of MOF-based devices [107]. In Figure 3 a pictorial sample of the world of MOF applications is shown.

At this point, the reader should think about the question first proposed in the introduction. Have the researchers of MOFs fully dominated the tailoring of the construction of porous framework materials aimed at functionality or the final application of them?

The diversity of the fabrication of metal-organic frameworks has not ended yet and neither has that of MOF-based devices. Indeed, the combination of MOFs with other functional materials producing new ones by tailoring 


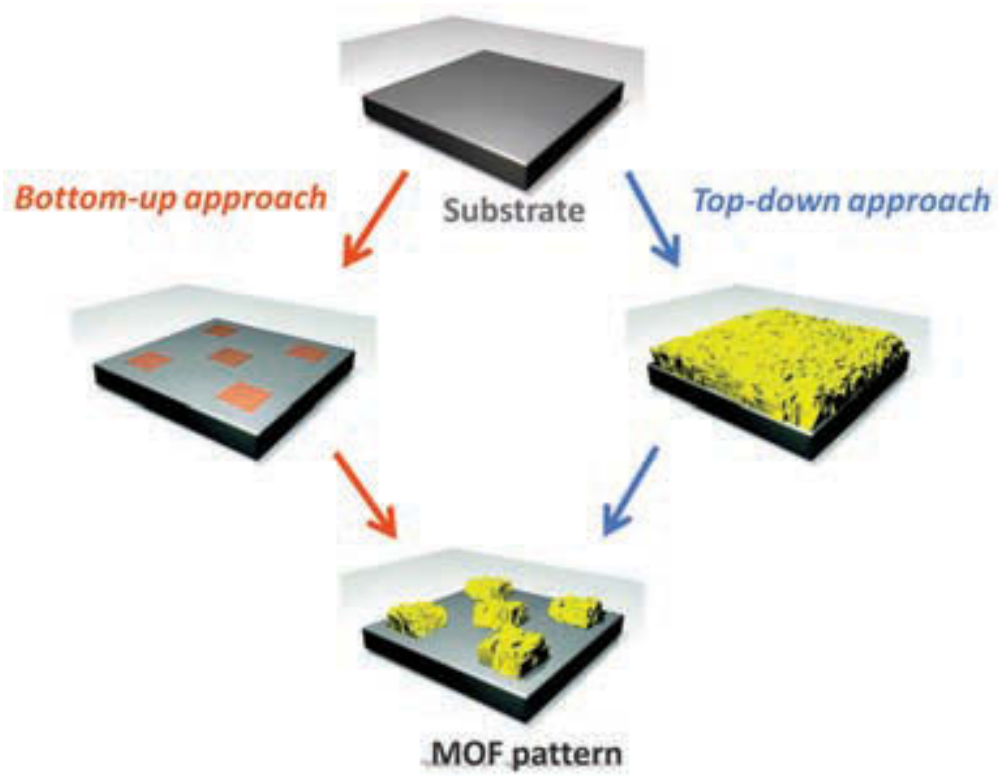

Figure 2. Scheme illustrating the bottom-up and top-down patterning approaches. Bottom-up patterning is defined here as any protocol, which grows MOF crystals in pre-identified locations, whereas top-down patterning is defined as the transfer or removal of pre-existing MOF crystals. Chem. Soc. Rev. vol. 43, p.5513-5560, 2014 - Published by The Royal Society of Chemistry.

and pre-designing them is certainly a hot area both in research and in technology. Thus, MOFs are excellent examples of a very fast transfer process from research knowledge to industry and final use [99,107]. Moreover, the integration of MOFs with functional materials in a miniaturized scale will certainly contribute to producing portable multiuse devices suitable for use in cell phones, electronic equipment, drug delivery compounds and especially, in new ways to store energy. There are, however, some key challenges that should be overcome to make these devices affordable for industrial, medicinal, and biotechnological applications. A remarkable example of these challenges has been delved in Chapter 10: the design and development of MOFs or MOF-based material with specific stimuli-responsive characteristics for drug delivery, which can be trigged by an external agent like light or temperature, or a biological condition of $\mathrm{pH}$ or concentration fluid.

\section{Zeolites and MOFs: from lab to industry}

Porous materials like zeolites and MOFs have attracted enormous attention from industry due to the great variety of technological applications that they 


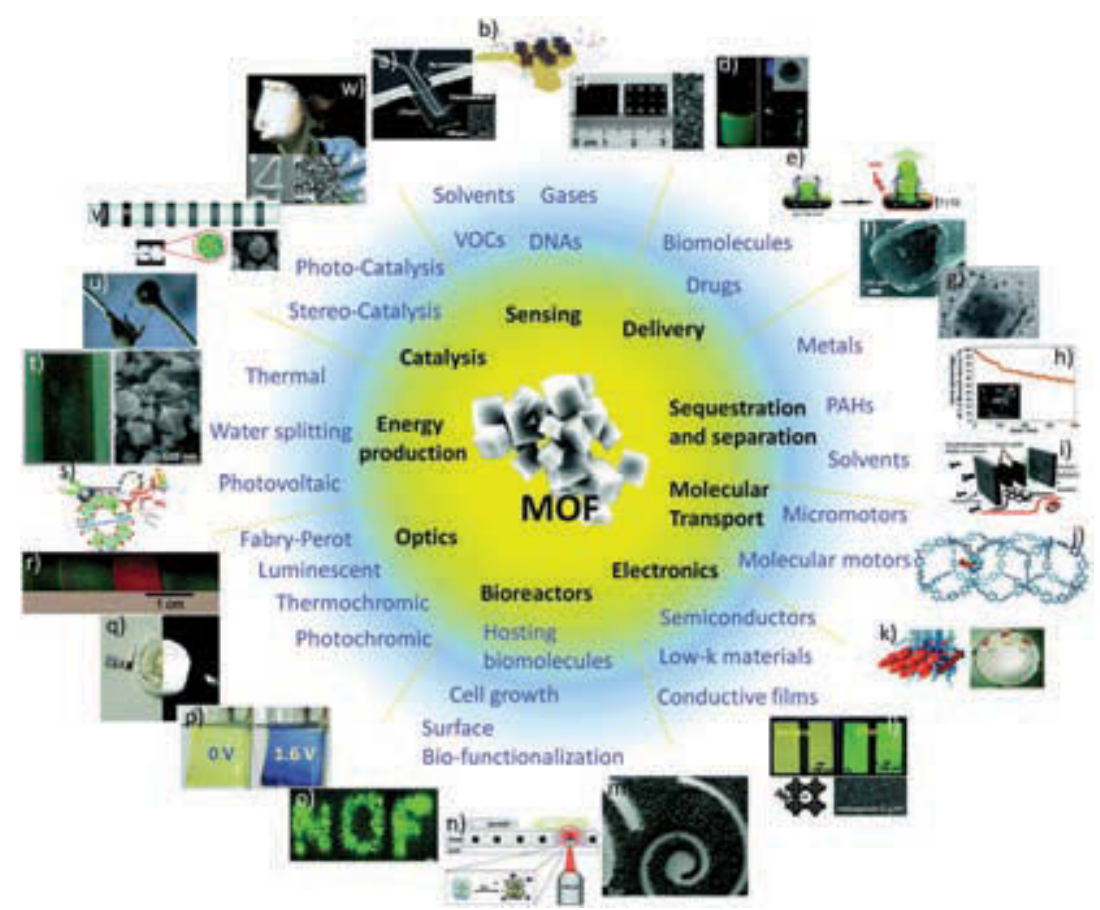

Figure 3. MOF-based devices a) MOF-based piezoresistive microcantilever, b) MOF-deposited gold QCM electrodes, c) HKUST-1 film on aluminium electrodes, d) magnetic manipulation of $\mathrm{Fe}_{3} \mathrm{O}_{4^{-}}$ loaded ZIF-8, e) near infrared-induced drug release from gold nanorod-loaded MOF, f) MOF-5coated fused-silica capillary, g) HKUST-1-coated silica magnetic bead, h) MOF-5 magnetic framework composite and the uptake of benzanthracene, i) HKUST-1 incorporated micro-separator assembly, j) porous aromatic framework structure with a highlighted $p$-phenylene rotor, $\mathrm{k}$ ) projection of a MOF-peptide 'boat' around the Petri-dish, I) TCNQ molecule entering a HKUST-1 film devices, m) MOF patterns created by UV lithography, n) photosensitive MOFs for cell activation, o) cell activation by irradiation-induced selective release of NO from MOF devices, p) MOF thin film-based reversible electrochromic device, q) MOF-based white emitting LED, r) ZIF-8-based Fabry-Perot interferometer, s) photoexcited organic linker induced electron transfer from the linker-to-cluster charge-transfer mechanism, t) MOF-coated doctor bladed $\mathrm{TiO}_{2}-\mathrm{MWCNTs}$ composite, $\mathrm{u}$ ) gold electrodes attached to a single MOF crystal, v) magnetic framework composite immobilized into a microfluidic catalytic system, w) HKUST-1 films on a photolithographed copper plate. Chem. Soc. Rev. 2014, 43, 5513-5560, and references therein. Published by The Royal Society of Chemistry.

already present. Both zeolites and MOFs have presented a considerable increase in the number of patents issued in the last decades - especially MOFs, which are more recent materials. However, these two kinds of materials exhibit different stages of maturity regarding their transfer to industry [99,108]. Whereas the worldwide consumption of zeolites ranges in the order of 5 million metric tons per year [108], MOFs are just beginning to be produced in large and commercialized scale in the last years, initially by BASF in association with Sigma Aldrich, followed by MOF Technologies and Strem [99]. 
Throughout the last decades, zeolites assumed a prominent role in industry and society in general, being used as detergents $(73 \%)$, adsorbents (10\%), and catalysts (17\%), especially for the petrochemical industry [109]. The expected tendency for zeolites is an increased demand in the catalysis sector, in important conversion processes such as methanol-to-olefins (MTO), methanol-to-gasoline (MTG), methanol-to-propylene (MTP) and, more recently, methane-to-benzene [109]. Nowadays, zeolite catalysts are being investigated, for instance, for their use in processes for the conversion of renewable resources and biodegradable wastes to valuable chemicals such as ethanol $[110,111]$. There is a closer relationship between the implementation of new processes in industry and the development and use of new or modified/existing zeolites due to some of their intrinsic properties of great porosity, selectivity, very high thermal stability, chemical stability, and an established route for large scale synthesis.

It is worth noting that, rather than competing with zeolites, MOFs take their place in some strategic and technological applications that do not demand severe conditions since they are, on average, stable up to 400$45^{\circ}{ }^{\circ} \mathrm{C}$ under air. Another issue to be considered when choosing MOFs or zeolites is their water resistance. Most MOFs cannot withstand water and, therefore, gases containing water have to undergo dehumidification. Nonetheless, MOFs such as Al-MOFs, commercially available as Basolite A-52O (Al(III)/fumaric acid) or Basolite A1oo (Al(III)/terephtahlic acid) [112], are extremely stable under vapor conditions, and, zeolitic imidazolate frameworks in particular, present high thermal and chemical stability [113].

The peculiar properties of MOFs with their extremely high adsorption capacity, polyfunctional architecture, tailor-made synthesis, high molecular selectivity, and fine arrangement of active sites have made them eligible for applications in a vast range of technologies. MOFs applications for industry comprise energy storage, gas storage and separation, fine organic synthesis, enantioselective synthesis and catalytic processes under mild conditions. Hydrogen and methane storage can be enhanced with the use of MOFs to an extent that makes hybrid hydrogen vehicles and higher autonomy methane cars a reachable and more environmental friendly reality. For hydrogen storage, Basolite Z377 (Zn(II)-benzene tribenzoate: MOF-177) has demonstrated the best result for prototype tank equipment with $32 \mathrm{~g}$ $\left(\mathrm{H}_{2}\right) \mathrm{L}^{-1}$ at $-196^{\circ} \mathrm{C}$ and $5 \mathrm{o}$ bar [109]. Regarding methane storage, MOFs adsorbent, namely Basolite $\mathrm{C}_{3} \mathrm{Oo}$, has already been used at room temperature in a Volkswagen Caddy Ecofuel using natural gas in a test tour from Berlin, to Bangkok, in 2007 [99]. The use of the MOF enhanced the tank capacity by $30 \%$, increasing the fuel autonomy by approximately $20 \%$ 
and reducing $\mathrm{CO}_{2}$ emission by 1.3 tons (compared to a $1.6 \mathrm{~L}$ gasoline car) [99]. Still, regarding energy and environmental applications, $\mathrm{CO}_{2}$ capture and separation have prominent roles [114] due to climate change and the $2{ }^{\circ} \mathrm{C}$ limit for global temperature increase established by the Paris Agreement [115]. In a comparative study employing MOFs, zeolitic MOFs and zeolites [116], MgMOF-74 was the best adsorbent for post-combustion $\mathrm{CO}_{2}$ capture. Indeed, several recent articles on $\mathrm{CO}_{2}$ capture by MOFs and MOFs composites [99,109,114,117-123] have already been published, and others are probably in progress. In addition, at the recent International Petroleum Exhibition \& Conference held in Abu Dhabi, UAE, in 2016, Mg-MOF-74 was confirmed as a promising $\mathrm{CO}_{2}$ material in pressure swing adsorption (PSA) and temperature swing adsorption (TSA), although zeolite ${ }_{13} \mathrm{X}(\mathrm{NaX})$ was regarded as preferential for the vacuum industrial process (VSA-vacuum swing adsorption), taking into consideration the current large-scale availability and the cost of both compounds [124].

Beyond gas storage and separation, catalytic processes and innovative MOF-based devices are becoming commercially available. In 2016, MOF Technologies in association with Queens University Belfast launched, a device called TruPick, which can be employed as a post-harvest freshness management tool for fruits and vegetables, that is already being used in the USA and is approved in Turkey [125]. Another ready-to-use product has been produced by NuMat Technologies in association with Northwestern University, who delivered a complete MOF-integrated product ready for the market instead of preparing only MOFs. They have fabricated ION-X cylinders, claimed to be the world's first commercial product to integrate Metal-Organic Frameworks for the storage and release of highly hazardous gases like arsine and phosphine used in the semiconductor industry [126]. NuMat executives have also reported that MOF-based products can also reach the end consumer, broadening the application for society, through their use in portable oxygen cylinders for people with chronic respiratory diseases [126]. In contrast to the petrochemical and environmental industry sector, which in many cases can preferably use zeolites, in the pharmaceutical industry MOFs can have paradigm-breaking uses in sensing, protecting enzymes and delivering drugs, taking into consideration their flexibility and compatibility to biological molecules.

In short, zeolites and MOFs are not competitors. Zeolites are in their prime, having been commercially used for decades. Many are stable at high temperatures and some can withstand water and drastic conditions. However, MOFs possess outstanding properties not only related to adsorption capacity but also to chemical flexibility. Technological advances will define 
the choice between zeolites and MOFs. In either case, challenges will have to be overcome to make them both economically accessible and properly tuned for large-scale use in industry and society, certainly, in many different applications.

\section{References}

[1] Gusenius, E.M. Trans. Kansas Academy of Science, 1969, 72, 476.

[2] McBain, J.W. The Sorption of Gases and Vapors by Solids, G. Routledge \& Sons, 1932.

[3] Barrer, R.M.J. Soc. Chem. Ind. 1945, 64, 130.

[4] Barrer, R.M.J. Chem. Soc. 1948, 2158.

[5] Barrer, R.M.J. Chem. Soc. 1948, 33, 127.

[6] Milton, R.M. in Zeolite Synthesis, ACS Symposium Series 398, 1, Occelli, M.L., Robson, H.E. (Eds.) Am. Chem. Soc. 1989.

[7] Reed, T.B., Breck, D.W.J. Chem. Soc. 1956, 78, 5972.

[8] Guisnet, M., Ribeiro, F.R. Zeólitos um nanomundo ao serviço da catálise, Fundação Calouste Gulbekian, 2004 (in Portuguese).

[9] Flanigen, E.M., Broach R.W. Wilson, S.T. in Zeolites in Industrial Separation and Catalysis, ch. 1, Kulprathipanja, S. (Ed.), Wiley-VCH, 2010.

[10] Sousa-Aguiar, E.F., Trigueiro, F., Zotin, F. Catal. Today 2013, 218, 115.

[11] Sousa-Aguiar, E.F. in Zeolites and Zeolite-Like Materials, p. 265, Kustov, L., Sels, B. (Eds.), Elsevier, 2016.

[12] Pace, G.G., Rendón, A.M., Fuentes, G.R. Zeolitas Características, Propiedades Y Aplicaciones Industriales, EdiT, 2000 (in Spanish).

[13] Breck, D.W. Zeolite Molecular Sieves, Krieger, 1984.

[14] Erdem, E., Karapinar, N., Donata, N. J. Colloid Interface Sci. 2004, 280, 309.

[15] Carocci, A., Rovito, N., Sinicropi, M.S., Genchi, G. in Reviews of Environmental Contamination and Toxicology, vol. 229, ch. 1, Whitacre, D.M. (Ed.), 2013.

[16] Wdowin, M., Franus, W. In Zeolites - Useful Minerals, ch. 4, Belviso, C. (Ed.), InTech, 2016.

[17] Zorpas, A.A., Constantinides, T., Vlyssides, A.G., Haralambous, I., Loizidou, M. Biores. Technol. $2000,72,113$.

[18] Shi, W.Y., Shao, H.B., Li, H., Shao, M.A., Du, S.J. Hazard. Mater. 2009, 170, 1.

[19] Lin, L., Wan, C., Lee, D.J., Lei, Z., Liu, X. Sep. Purif. Technol. 2014, 133, 351.

[20] Ho, L., Ho, G. Water Res. 2012, 46, 4339.

[21] Markou, G., Vandamme, D., Muylaert, K. Biores. Technol. 2014, 155, 373.

[22] Rhodes, C.J. Sci. Prog. 2010, 93, 1.

[23] Barczyk, K., Mozgawa, W., Krói, M. Spectrochim. Acta A 2014, 133, 876.

[24] Sadeghi, A.A., Shawrang, P. Livest. Sci. 2008, 113, 307.

[25] Fukahori, S., Fujiwara, T., Ito, R., Funamizu, N. Desalination 2011, 275, 237.

[26] Pasquino, R., Di Domenico, M., Izzo, F., Gaudino, D., Vanzanella, V., Grizzuti, N., de Gennaro, B. Colloid Surf. B 2016, 146, 938.

[27] Farıas, T., Ruiz-Salvador, A.R., Rivera, A. Microp. Mesop. Mater. 2003, 61, 117.

[28] Sircar, S., Myers, A.L. in Handbook of Zeolite Science and Technology, ch. 22, Auberbach, S.M., Carrado, K.A., Dutta, P.K. (Eds.), Marcel Dekker, 2003.

[29] Ackley, M.W., Rege, S.U., Saxena, H. Microp. Mesop. Mater. 2003, 61, 25.

[30] Mitchell, L. Adsorption of Light Gases and Gas Mixtures on Zeolites and Nanoporous Carbons, Ph.D. thesis, Vanderbilt University, 2014. 
[31] Vermesse, J., Vidal, D, Malbrunot, P. Langmuir, 1996, 12, 4190.

[32] Sapag, K., Vallone, A., Blanco, A.G., Solar, C. in Natural Gas, ch. 1o, Potocnik, P. (Ed.) Intech, 2010.

[33] Li, M., Zhu, X., Zhu, F., Ren, G., Cao, G., Song, L. Desalination, 2011, 271, 295.

[34] Hrenovic, J., Ivnkovic, T., Rajiic, N.J. Hazard. Mater. 2012, 201, 260.

[35] Krishnani, K.K., Zhang, Y., Xiong, L., Yan, Y., Boopathy, R., Mulchandani, A. Biores. Technol. $2012,117,86$.

[36] Inoue, Y., Hoshino, M., Takahashi, H., Noguchi, T., Murata, T., Kanzaki, Y., Hamashima, H., Sasatsu, M. J. Inorg. Biochem. 2002, 92, 37.

[37] Matsumura, Y., Yoshikata, K., Kunisaki, S.I., Tsuchido, T. Appl. Environ. Microb. 2003, 69, 4278.

[38] Dong, L.X., Yang, H.W., Liu, S.T., Wang, X.M., Xie, Y.F. Desalination, 2015, 365, 70.

[39] Kim, S.G., Hyeon, D.H., Chun, J.H., Chun, B.H., Kim, S.H.J. Membrane Sci. 2013, 443, 10.

[40] Dong, H., Zhao, L., Zhang, L., Chen, H., Gao, C., Winston Ho, W.S.J. Membrane Sci. 2015, 476, 373 .

[41] Ahmadiannamini, P., Eswaranandam, S., Wickramasinghe, R., Qian, X. J. Membrane Sci. 2017, 526, 147 .

[42] Yurekli, Y.J. Hazard. Mater. 2016, 309, 53.

[43] Hosseini, S.M., Rafiei, S., Hamidi, A.R., Moghadassi, A.R., Madaeni, S.S. Desalination, 2014, 351,138 .

[44] Muresan, L.M. Pure Appl. Chem. 2011, 83, 325 .

[45] Kucherenko, I., Soldatkin, O., Kasap, B.O., Kirdeciler, S.K., Kurc, B.A., Jaffrezic-Renault, N., Soldatkin, A., Lagarde, F., Dzyadevych, S. Nanoscale Res. Lett. 2015, $10,1$.

[46] Senthilkumar, S., Saraswathi, R. Sens. Actuators B Chem. 2009, 141, 65.

[47] Urbiztondo, M., Pellejero, I., Rodriguez, A., Pinaa, M.P., Santamaria, J. Sens. Actuators B Chem. 2011, 157, 450.

[48] Marcilly, C. Oil Gas Sci. Technol. 2001, 56, 499.

[49] Sedran, U. Catal. Rev. 1994, 36, 405.

[50] Sousa-Aguiar, E.F., Camorim, V., Zotin, F., Santos, R. Microp. Mesop. Mater. 1998, 25, 25.

[51] Sousa-Aguiar, E.F., Monteiro, D., Trigueiro, F., Zotin, F.J. Alloy. Compd. 2002, 344, 337.

[52] Sousa-Aguiar, E.F., Baugis, G., Castro, F.R., Oliveira, W., Brito, H. Microp. Mesop. Mater. 2001, 49, 179 .

[53] Jonker, R.J., O'Connor, P., Nicolaas, H., Wijngaards, J. US Patent 6828153 B2, 2004.

[54] O'Connor, P., Olthof, F.P., Smeink, R., Coopmans, J. in Fluid Cracking Catalysts, Ch. 6, Occelli, O'Connor (Eds.), Marcel Dekker, 1998.

[55] Fletcher, R., Hakuli, A., Imhof, P. Oil Gas J. 2002, 100, 54.

[56] Rainer, D., Rautiainen, E., Nelissen, B., Imhof, P., Vadovic, C. Stud. Surf. Sci. Catal. 2004, 149, 165 .

[57] O'Connor P., Berends, E. US Patent 6930067, 2005.

[58] Sousa-Aguiar, E.F., Murta-Valle, M.L., Sobrinho, E.V., Cardoso, D. Stud. Surf. Sci. Catal. 1995, 97,417 .

[59] Al-Khattaf, S., Atias, J.A., Jarosch, K., de Lasa, H. Chem. Eng. Sci. 2002, 57, 4909.

[6o] Costa, A.F., Cerqueira, H.S., Sousa-Aguiar, E.F., Ludvig, M.M. Stud. Surf. Sci. Catal. 2004, 154-C, 2296.

[61] Li, K., Valla, J., Garcia-Martinez, J. ChemCatChem, 2014, 6, 46.

[62] Rahim, N., Karimzadeh, R. Appl. Catal., A 2011, 398, 1.

[63] Blasco, T., Corma, A., Martínez-Triguero, J.J. Catal. 2006, 237, 267.

[64] Lee, J., Hong, U.G., Hwang, S., Youn, M.H., Song, I.K. Fuel Process. Technol. 2013, 109, 189.

[65] Wang, Q. EP Patent o801027 $A 7,1997$. 
[66] Vogt, E., Weckhuysen, B. Chem. Soc. Rev. 2015, 44, 7342.

[67] Sousa-Aguiar, E.F., Bellot Noronha, F., Faro Jr., A. Catal. Sci. Technol. 2011, 1, 698.

[68] Prada Silvy, R., Santos, A.C.B., Sousa-Aguiar, E.F. Oil Gas J. 2010, 108, 5170498171.

[69] Bouchy, C., Hastoy, G., Guillon, E., Martens, J.A. Oil Gas Sci. Technol. 2009, 64, 91.

[70] Leckel, D. Energy Fuel. 2009, 23, 2370.

[71] Dupain, X., Krul, R., Schaverien, C., Makkee, M., Moulijn, J. Appl. Catal., B 2006, 63, 277.

[72] Calemma, V., Gambaro, C., Parker Jr., W.O., Carbone, R., Giardino, R., Scorletti, P. Catal. Today, 2010, 149, 40.

[73] Thybaut, J.W., Choudhury, I.R., Denayer, J.F., Baron, G.V., Jacobs, P.A., Martens, J.A. Marin, G.B. Top. Catal. 2009, 52, 1251.

[74] Arroyo, J.A.M., Martens, G.G., Froment, G.F., Marin, G.B., Jacobs, P.A., Martens, J.A. Appl. Catal., A 2000, 192, 9.

[75] Denayer, J., Baron, G.V., Vanbutsele, G., Jacobs, P.A., Martens, J.A. Chem. Eng. Sci. 1999, 54, 3553.

[76] Denayer, J.F., Ocakoglu, A.R., Huybrechts, W., Martens, J.A., Thybaut, J.W., Marin, G.B., Baron, G.V. Chem. Commun. 2003, 15, 188o.

[77] Denayer, J.F., Souverijns, W., Jacobs, P.A., Martens, J.A., Baron, G.V.J. Phys. Chem. B 1998, 102, 4588 .

[78] Laxmi Narasimhan, C.S., Thybaut, J.W., Marin, G.B., Martens, J.A., Denayer, J.F., Baron, G.V. J. Catal. 2003, 218, 135 .

[79] Martens, J.A., Vanbutsele, G., Jacobs, P.A., Denayer, J., Ocakoglu, R., Baron, G.V., Muñoz Arroyo, J.A., Thybaut, J., Marin, G B., Catal. Today, 2001, 65, 111.

[8o] Souverijns, W., Martens, J.A., Froment, G.F., Jacobs, P.A. J. Catal. 1998, 174, 177.

[81] Verdier, S., Coutinho, J.A.P., Silva, A.M.S., Alkilde, O.F., Hansen, J.A. Fuel, 2009, 88, 2199.

[82] Miller, S.J., O'rear, D.J., Rosembaum, J.M. WO Patent 2005037963 A2, 2005.

[83] Deldari, H. Appl. Catal., A 2005, 293, 1.

[84] Yaghi, O.M., Li, H.J. Am. Chem. Soc. 1995, 117, 10401.

[85] Férey, G. Chem. Soc. Rev. 2008, 37, 191.

[86] Kuppler, R.J., Timmons, D.J., Fang, Q.R., Li, J.R., Makal, T.A., Young, M.D., Yuan, D., Zhao, D., Zhuang, W., Zhou, H.C. Coord. Chem. Rev. 2009, 253, 3042.

[87] Yaghi, O.M., Davis, H., Li, C., Richardson, D., Groy, T.L. Acc. Chem. Res. 1998, 31, 474.

[88] Yaghi, O.M., O'Keeffe, M., Ockwig, N.W., Chae, H.K., Eddaoudi, M., Kim, J. Nature 2003, 423, 705.

[89] Rowsell, J.L.C., Yaghi, O.M. Microp. Mesop. Mater. 2004, 73, 3.

[9o] Meier, W.M., Olson, D.H. Atlas of Zeolite Framework Types, Elsevier, 2001.

[91] O'Keeffe, M., Eddaoudi M., Hailian Li, Reineke, T., Yaghi, O.M. J. Solid State Chem. 2ooo, $15^{2,}, 3$.

[92] Férey, G.J. Solid State Chem. 200o, 152, 37.

[93] Motoyama, S., Makiura, R., Sakata, O., Kitagawa, H.J. Am. Chem. Soc. 2011, 133, 5640.

[94] Furukawa, H., Cordova, K.E., O’Keeffe, M., Yaghi, O.M. Science, 2013, 341, 974.

[95] Lu, W., Wei, Z., Gu, Z.Y., Liu, T.F., Park, J., Park, J., Tian, J., Zhang, M., Zhang, Q., Gentle 3rd, T., Bosch, M., Zhou, H.C. Chem. Soc. Rev. 2014, 43, 5561.

[96] Alezi, D., Belmabkhout, Y., Suyetin, M., Bhatt, P.M., Weseliński, Ł.J., Solovyeva, V, Adil, K., Spanopoulos, I., Trikalitis, P.N., Emwas, A.H., Eddaoudi, M. J. Am. Chem. Soc. 2015, 137, 13308.

[97] Ribeiro, J.S., Costa, E.S., Hatimondi, S.A., Miranda, J.L. Revista Virtual da Química, 2014, 6, 1172 .

[98] Bhattacharjee, S., Chenab, C., Ahn, W.S. RSC Adv. 2014, 4, 52500.

[99] Silva, P., Vilela, S.M.F., Tomé, J.P.C., Paz, F.A.A. Chem. Soc. Rev. 2015, 44, 6774.

[10o] Li, J.R., Timmons, D.J., Zhou, H.C.J. Am. Chem. Soc. 20o9, 131, 6368. 
[101] Meilikhov, M., Yusenko K., Fischer, R.A.J. Am. Chem. Soc. 2009, 131, 9644.

[102] Mondloch, J.E., Bury, W., Fairen-Jimenez, D., Kwon, S., de Marco, E.J., Weston, M.H., Sarjeant, A.A., Nguyen, S.T., Stair, P.C., Snurr, R.Q., Farha, O.K., Hupp, J.T.J. Am. Chem. Soc. 2013, 135, 10294.

[103] Deria, P., Mondloch, J.E., Karagiaridi, O., Bury, W., Hupp, J.T., Farha, O.K. Chem. Soc. Rev. 2014, 43, 5896.

[104] Eddaoudi, M., Sava, D.F., Eubank, J.F., Adila, K., Guillerm, V. Chem. Soc. Rev. 2015, 44, 228.

[105] Sue, A.C.H., Mannige, R.V., Deng, H., Cao, D., Wang, C., Gándara, F., Stoddart, J.F., Whitelam, S., Yaghi, O.M. PNAS 2015, 112, 5591.

[106] Wang, H., Zhu, Q.L., Zou, R., Xu, Q. Chem 2017, 2, $5^{2}$.

[107] Falcaro, P., Ricco, R., Doherty, C.M., Liang, K., Hill, A.J., Styles, M.J. Chem. Soc. Rev. 2014, 43, 5513.

[108] Davis S, Inoguchi Y. In Zeolites - Chemical Economics Handbook, ch. 6, SRI Consulting, 2009.

[109] Yilmaz, B., Trukhan, N., Müller, U. Chinese J. Catal. 2012, 33, 3.

[110] Taarning, E., Osmundsen, C.M., Yang, X., Voss, B., Andersen, S.I., Christensen, C.H. Energy Environ. Sci. 2011, 4 (3), 793.

[111] Messina, L.I.G., Bonelli, P.R., Cukierman, A.L. Fuel Process. Technol. 2017, 159, 160.

[112] Leung, E., Müller, U., Cox, G., Mattenheimer, H., Blei, S. EP Patent 10183283.o, 2010.

[113] Park, K.S., Ni, Z., Côte, A.P., Choi, J.Y., Huang, R., Uribe-Romo, F.J., Chae, H.K., O'Keeffee, M., Yaghi, O.M. PNAS 2006, 103, 10186.

[114] Sumida, K., Rogow, D.L., Mason, J.A., McDonald, T.M., Bloch, E.D., Herm, Z.R., Bae, T.H., Long, J.R. Chem. Rev. 2012, 112, 724.

[115] https://unfccc.int/resource/docs/2015/cop21/eng/lo9

[116] Krishna, R., van Baten, J.M. Sep. Purif. Technol. 2012, 87, 120.

[117] Wang, H.H., Shi, W.J., Hou, L., Li, G.P., Zhu, Z., Wang, Y.Y. Chem. Eur. J. 2015, 21, 16525.

[118] Chen, D.M., Tian, J.M., Chen, M., Liu, S., Du, M.C. ACS Appl. Mater. Inter. 2016, 8, 18043.

[119] Ye, Y., Xiong, S., Wu, X., Zhang, L., Li, Z., Wang, L., Ma, X., Chen, Q.H., Zhang, Z., Xiang, S. Inorg. Chem. 2016, 55, 292.

[120] Li, S., Chung, Y.G., Snurr, R.Q. Langmuir, 2016, 32, 10368.

[121] Nandi, S., Collins, S., Chakraborty, D., Banerjee, D., Thallapally, P.K., Woo, T.K., Vaidhyanathan, R.J. Am. Chem. Soc. 2017, 139, 1734.

[122] Sargazi, G., Afzali, D., Mostafavi, A., Ebrahimipour, S.Y.J. Solid State Chem. 2017, 25०, 32.

[123] Zhu, C.J. Mol. Struct. 2017, 1136, 140.

[124] Vega, L.F., Bahamon, D. Comparative Study of MOFs and Zeolites For CO Capture and Separation at Process Conditions, Abu Dhabi International Petroleum Exhibition \& Conference, 7-10 November, 2016.

[125] Editorial, Nat. Chem. 2016, 8, 987 .

[126] Faust, T. Nat. Chem., 2016, 8, 990. 